\title{
Genetic Diversity, Distribution, and Serological Features of Hantavirus Infection in Five Countries in South America
}

\author{
P. J. PADULA, ${ }^{1 *}$ S. B. COLAVECCHIA,${ }^{1}$ V. P. MARTÍNEZ ${ }^{1}$ M. O. GONZALEZ DELLA VALLE, ${ }^{1}$ \\ A. EDELSTEIN, ${ }^{1}$ S. D. L. MIGUEL, ${ }^{1}$ J. RUSSI, ${ }^{2}$ J. MORA RIQUELME ${ }^{3}$ N. COLUCCI, ${ }^{4}$ \\ M. ALMIRÓN, ${ }^{5}$ AND R. D. RABINOVICH ${ }^{1}$ \\ Departamento de Virología, Instituto Nacional de Enfermedades Infecciosas, A.N.L.I.S. "Dr. Carlos G. Malbrán," \\ 1281 Buenos Aires, Argentina ${ }^{1}$; Departamento de Laboratorios, Ministerio de Salud Pública, 11600 Montevideo, \\ Uruguay ${ }^{2}$; Seccion Virología, Instituto de Salud Pública, Ministerio de Salud Pública de Chile, Casilla 48, \\ Santiago, Chile ${ }^{3}$; Laboratorio Central de Salud Pública, Ministerio de Salud Pública y Bienestar Social, \\ Asunción, Paraguay ${ }^{4}$; and Instituto de Investigaciones en Ciencias de la Salud, Universidad Nacional \\ de Asunción, Río de la Plata y Lagerenza, Asunción, Paraguay ${ }^{5}$
}

Received 13 January 2000/Returned for modification 5 April 2000/Accepted 30 May 2000

\begin{abstract}
Since 1995 when the first case of hantavirus pulmonary syndrome (HPS) was reported in Patagonia, there have been more than 400 cases of HPS reported in five countries in South America. The first case of HPS was associated with Andes (AND) virus. In this study, we report on the genetic diversity, geographical distribution, and serological features of hantavirus infection in six countries in South America based on 87 HPS cases from Argentina, Bolivia, Chile, Paraguay, and Uruguay. An early immunoglobulin M (IgM), IgA, and IgG humoral response was observed in almost all HPS cases. The IgM response appears to peak 1 or 2 days after the onset of symptoms. Peak IgG antibody titers occur mostly after the first week. Low IgG titers or the absence of IgG was associated with higher mortality rates. The IgA response peaks around day 15 and then rapidly decreases. The results of phylogenetic analysis based on partial M-fragment G1- and G2-encoding sequences showed that HPS cases from the five countries were infected with viruses related to AND or Laguna Negra (LN) virus. Within AND virus-infected persons, at least five major genetic lineages were found; one lineage was detected in Uruguayan and Argentinean cases from both sides of the Rio de la Plata river. Two Paraguayan patients were infected with a virus different from $\mathrm{LN}$ virus. According to the results of phylogenetic analyses, this virus probably belongs to a distinct lineage related more closely to the AND virus than to the LN virus, suggesting that there is probably an Oligoryzomys-borne viral variant circulating in Paraguay. These studies may contribute to a better understanding of hantavirus human infection in South America.
\end{abstract}

The hantaviruses (family Bunyaviridae) are enveloped viruses with a tripartite negative-sense RNA genome. The three genomic segments $\mathrm{S}, \mathrm{M}$, and L code for a nucleocapsid protein $(\mathrm{N})$, two envelope glycoproteins ( $\mathrm{G} 1$ and $\mathrm{G} 2)$, and a viral transcriptase, respectively $(5,23)$. Several members of the genus Hantavirus including Seoul (SEO), Hantaan (HTN), Dobrava (DOB) carried by Murinae rodents, and Puumala (PUU) carried by an Arvicolinae rodent are associated with hemorrhagic fever with renal syndrome (HFRS) (11). In 1993, a new illness associated with sigmodontineborne hantaviruses, hantavirus pulmonary syndrome (HPS), in North America was described (4, 9, 10). The causative agent was Sin Nombre (SN) virus (18), which is responsible for most of the HPS cases in North America; however, many other HPS-associated viruses have been discovered in recent years.

Since 1995 when the first HPS case in Patagonia was associated with Andes virus (AND) (13), more than 400 HPS cases have been reported in six countries of South America: Argentina, Bolivia, Brazil, Chile, Paraguay, and Uruguay. The mortality rate was high, ranging from $70 \%$ for the first cases to $30 \%$ for more recent outbreaks.

Several differences between South and North American han-

* Corresponding author. Mailing address: Departamento de Virología, Instituto Nacional de Enfermedades Infecciosas, A.N.L.I.S. "Dr. Carlos G. Malbrán,” Av. Velez Sarsfield 563, 1281 Buenos Aires, Argentina. Phone and fax: (54-11) 4301-3146. E-mail: ppadula @cvtci.com.ar. tavirus infection were observed. High seroprevalence levels in Indian populations inhabiting Paraguayan and Argentinean sectors of the Gran Chaco were observed $(7,30)$. Person-toperson transmission has been demonstrated for Andes (AND) virus in Argentina (19) and are likely for the two family clusters in Chile (27). Also, cases in South America differed in some clinical characteristics: renal insufficiency and elevated creatinine kinase levels were observed at much higher frequency, and proteinuria, myositis, and conjunctival injection showed more severe manifestations (25).

In phylogenetic analysis, all sigmodontine hantaviruses from six countries in South America clustered together and in a different group from that of North American viruses $(8,12,13$, 20). Although several viral lineages carried by different rodent species have been reported, an exhaustive study of genotypes associated with human infection according to geographical localization has not been done. The relationship between phenotype and clinical manifestation has not been elucidated. The kinetics of the immune response and serological prognostic markers of different stages of infection have not been determined.

To determine the genotypes and distribution of hantavirus causing HPS in five countries in South America, we conducted a nucleotide sequence analysis of HPS-associated viruses from the region. In addition, we studied the serological response and its relationship with the stage of disease in these patients and the probability of dying from the infection. 


\section{MATERIALS AND METHODS}

Study population. Routine serum samples from suspected HPS cases from Argentina, Chile, Paraguay, and Uruguay were collected during a 4-year period. Eighty-seven patients were confirmed as having hantavirus by serology. A total of 147 acute, early convalescent, and late-convalescent phase ( 3 to 13 months) sera were available from these patients. The study included 70 males and 17 females aged 3 to 65 years. Clinical and pathologic findings could distinguish two illness severities: 52 severe HPS cases, 48 of which required mechanical ventilation, and 29 mild cases with lower respiratory compromise associated with myalgia, fever, and headache. Clinical data from six cases were not available.

Serology. For detection of AND virus-specific immunoglobulin $\mathrm{G}(\mathrm{IgG})$ and IgA antibodies, enzyme-linked immunosorbent assay (ELISA) was performed on serum samples as previously described (20). Briefly, patient and control sera were diluted 1:100 and fourfold up to 1:6,400. A recombinant AND nucleoprotein $(\mathrm{N})$ was used as a specific antigen. For IgM detection, a $\mu$-capture ELISA was performed using the same recombinant antigen and rabbit hyperimmune serum as a second antibody. Signal reaction was detected using 2,2'-azinobis(3ethylbenzthiazolinesulfonic acid) (ABTS) as a substrate for peroxidase. Sera with an optical density of $>0.3$ were considered positive. All commercial reagents were from Kirkegaard and Perry.

Statistical analysis. Antibody responses between surviving and nonsurviving patients were tested for differences by Student's $t$ test (two tailed). Differences were considered significant at $P$ of $<0.05$. Epilnfo version 6.04 (Centers for Disease Control and Prevention, Atlanta, Ga.) was used to calculate $t$ test and odds ratios.

RNA extraction, reverse transcription-polymerase chain reaction (RT-PCR), and sequencing. Total RNA was extracted from blood samples, clots, sera, or organs of HPS patients using the guanidinium isothiocyanate-acid phenol extraction procedure as described previously (13). For RNA purification, the RNaid kit (Bio101) was utilized following the manufacturer's recommendations.

Partial S and M segments were amplified by RT-PCR followed by a second round of nested or heminested PCR. Specific oligonucleotide primers based on conserved regions of AND virus genome were used. Sequences and positions of the primers have been described elsewhere $(19,20)$. Positions of the $\mathrm{S}$ and $\mathrm{M}$ segments fragments were numbered relative to those of AND and SN viruses, respectively. Amplification products were separated on agarose gels, gel purified, and manually sequenced by the dideoxy cycle sequencing technique (fmol DNA Sequencing System; Promega) or by the fluorescent sequencing technique (dRhodamine Terminator Cycle Sequencing kit; Applied Biosystem) using an ABI 377 automatic sequencer.

Phylogenetic and comparative sequence analyses. Multiple-sequence alignment and comparison of nucleotide and deduced amino acid sequences were performed using CLUSTAL V, a PCGENE 6.8 software program of Intelligenetics Inc. (Mountain View, Calif.).

Maximum-parsimony (MP) and neighbor-joining analyses of nucleotide and putative amino acid sequence viruses were performed using the PHYLIP (Phylogeny Inference Package), version 3.57c. (J. Felsenstein, University of Washington, Seattle, Wash.). DNAPARS and PROTPARS programs were used to obtain MP trees for nucleotide and protein sequences, respectively. The lengths of the tree stems are proportional to genetic distances obtained using the DNADIST program for nucleotide analyses, weighing transversion twice as transitions; meanwhile for protein sequences, distances were obtained using the PROTDIST program with the Dayhoff substitution matrix. The FITCH program was used to fit distances to MP trees.

The following published M-segment sequences were included in the analysis: New York (NY) virus Rhode Island-1, U36801; Sin Nombre (SN) virus, L25783; Lechiguanas (LEC) virus strain, Af028022; Laguna Negra (LN) virus, Af005728; Bayou (BAY) virus, L36930; Black Creek Canal (BCC) virus, L39950; Puumala (PUU) virus Sotkamo strain, X61034; Prospect Hill (PH) virus, X55129; Seoul (SEO) virus, M34882; and Hantaan (HTN) virus, M14627.

\section{RESULTS}

Serological response. A total of 147 blood or serum samples were collected from 87 patients and tested for antibodies and/or viral genome to establish the viral genome and serological reactivity for immunoglobulins to AND virus nucleoprotein after hantavirus infection.

The IgM, IgG, and IgA responses in HPS patients over time is presented in Fig. 1. The IgM response appears to peak 1 or 2 days after the onset of symptoms and is detected in serum for up to 2 months. Mean IgG antibody titers peak slightly later than the mean for $\operatorname{IgM}$, mostly after the first week and reach the maximum optical density levels around day 17 . Thirty days after the onset of symptoms, IgG exceeds 25,600 reciprocal end titers in most of the cases. No significant decrease in $\mathrm{IgG}$ antibody titers was observed during the 13-month study period.
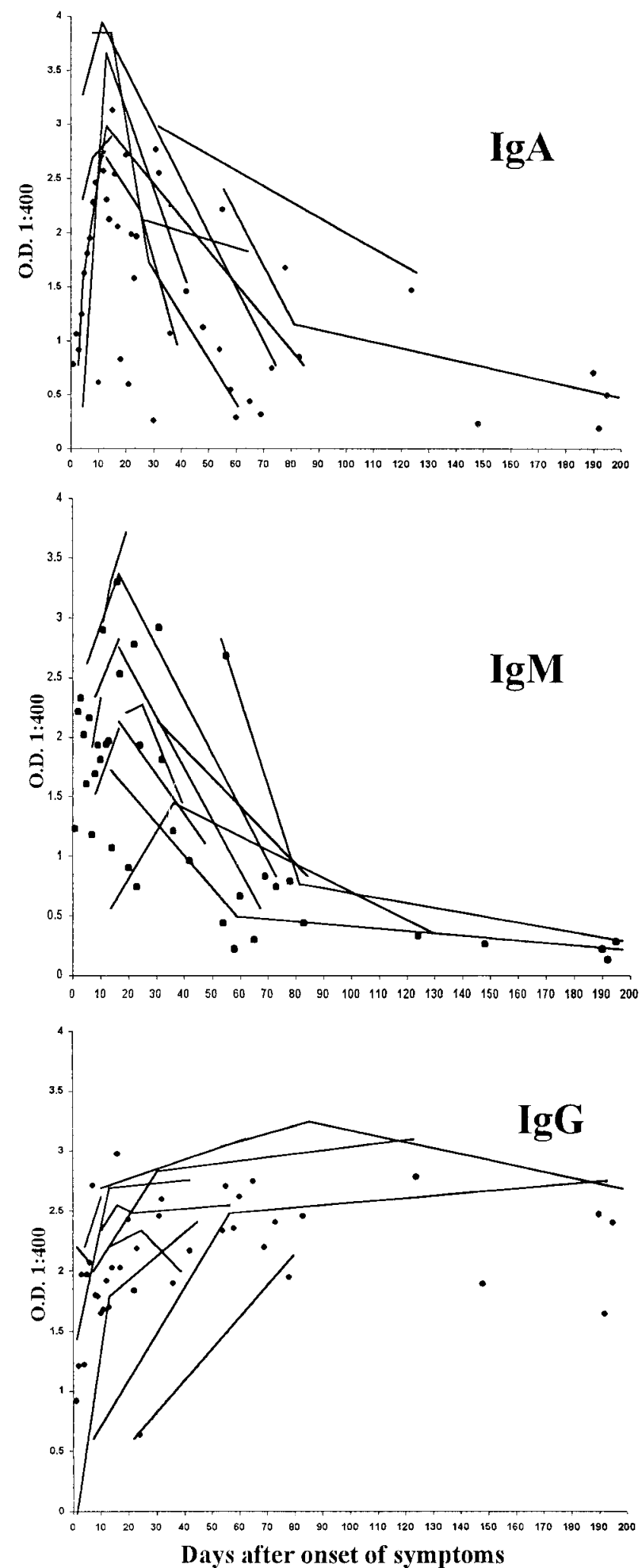

FIG. 1. Andes virus-specific $\operatorname{IgG}$, IgA, and IgM antibody responses in 147 HPS acute or recent convalescent serum samples. Assay results on sera collected from one individual at different times are shown connected by a line. Each point represents the median daily value for the data group studied. O.D., optical density. 


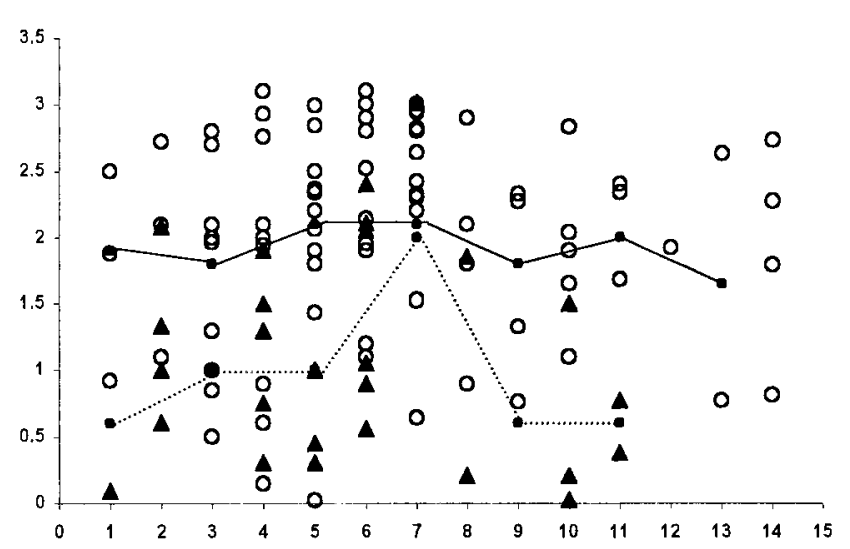

FIG. 2. IgG responses in surviving $(\bigcirc)$ and nonsurviving $(\boldsymbol{\Delta})$ patients with acute infections of AND virus. Time (in days after onset of symptoms) is shown on the $x$ axis, and optical density (1:400) is shown on the $y$ axis. The data for five children less than 13 years old who died and six children less than 13 years who survived are included here. The solid line represents the mean $\mathrm{IgG}$ values for survivors; the dotted line represents the mean $\operatorname{IgG}$ values for nonsurvivors (each point [0] is the average $\operatorname{IgG}$ value for a consecutive 2-day interval).

The first samples available from almost all patients were positive for IgM. The exception was two acute cases in Northern Argentina; for a few days, IgM could not be detected, although RT-PCR and IgG were positive. The IgA response was similar to the IgM response, reaching high levels around day 15 . However, in some patients, the IgA curve showed a more pronounced decline than the IgM curve. Considering this finding, high levels of serum-specific IgA could be highly indicative of an acute infection.

In a comparison of patients who died and those who survived, we observed lower IgG antibody values against AND N protein in the patients who died than in those who survived (Fig. 2) in both children and adult patients. Using Student's $t$ test, significant differences in $\mathrm{IgG}$ values between survivors and nonsurvivors were obtained in intervals of 3 to 4,5 to 6 , and 10 to 13 days after onset of symptoms. In order to analyze the usefulness of specific IgG data for predicting whether patients survived, the odds ratio for a value below the median antibody response for all patients was calculated using the first sample available. For the 91 patients, the odds ratio (95\% confidence interval) obtained was 6.45 (2.14 to 20.14) $(P=0.0003)$.

Either M- or S-fragment segments were detected by RTPCR in 81 of 87 samples from patients with acute infection between 1 to 30 days after the onset of symptoms. For HPS contact studies, we collected samples prior to the onset of symptoms. The viral genome could be detected using RT-PCR in a sample obtained 7 days before the onset of symptoms; however, no viral genome was amplified between days 10 to 26 prior to the illness.

Phylogenetic analyses and geographic distribution. In order to determine which hantavirus lineage is associated with human infections in five countries in South America (Argentina, Bolivia, Chile, Paraguay, and Uruguay), a MP phylogenetic analysis based on nucleotide differences in M-segment PCR fragments of the G1-coding region (positions 88 to 281 and 1736 to 1987 ) and a fragment of the G2-coding region (positions 2721 to 2946 ) of the cases we studied and other hantaviruses was performed (Fig. 3). All the cases we studied were related to AND or Laguna Negra (LN) virus variants (Fig. 3A). There are at least five different genetic lineages within AND virus (strongly supported by high bootstrap values) from human cases. The AND Sout lineage was characterized from
South Argentinean and Chilean patients. These sequences clustered together with the Epilink/96 sequence, which was associated with 16 cases of person-to-person transmission (19). The AND Nort lineage was observed in North Argentine provinces (Jujuy and Salta), including the previously reported Oran genotype (12). In the central region of Argentina, two different lineages were found. The AND Cent Bs.As. lineage includes the Hu39694 genotype previously reported. The AND Cent Lec lineage clustered with the Lechiguanas (LEC) genotype described previously (12). The AND Cent BsAs lineage was detected in several locations of Buenos Aires province, and the AND Cent Lec lineage was detected near the river regions. A new lineage named AND Cent Plata was characterized from cases from both sides of the Rio de la Plata river (Argentina and Uruguay). The AND Cent Bs.As. lineage was more prevalent near the central Argentine region, where it accounts for $80 \%$ of infections. Nucleotide and amino acid identities among AND lineages ranged from 76.5 to $86.6 \%$ and 91.9 to $96.9 \%$, respectively (Table 1 ).

From the six viruses characterized from Paraguayan patients, four viruses were characterized as LN. The other two patients were infected with very similar viruses, although around $25 \%$ nucleotide and $16 \%$ amino acid divergences were found when these viruses were compared to $\mathrm{LN}$ virus for the 672-nucleotide (nt) sequence analyzed. When comparing with the AND virus lineages, nucleotide and amino acid identities ranged from 78.6 to $80.6 \%$ and 93.2 to $95.0 \%$, respectively. These sequences clustered with the AND virus in parsimony phylogenetic analysis supported by a high bootstrap value (94\%). The Arg-Bol/98 virus belongs to an Argentinean patient who worked in Bolivia but was hospitalized in North Argentina near the border with Bolivia. This sequence clustered with the $\mathrm{LN}$ virus.

The topology of the tree based on the amino acid sequence obtained using MP analysis (Fig. 3B) is very similar to the one obtained using nucleotide sequence. However, in the amino acid analysis, the distances within the AND virus cluster are much smaller than those obtained for other clusters. Phylogenetic analysis performed using the neighbor-joining method produced a tree (not shown) very similar to the tree obtained using the MP method.

Severe and moderate cases were found among persons infected with any of the five AND virus lineages. There have been some reported cases of clear hemorrhagic signs associated with infection with viruses belonging to the AND Sout, AND Nort, and AND Cent Bs.As. lineages.

Lineages and genetic variations of HPS hantaviruses. Several regions of the AND virus genome have been analyzed with the purpose of furthering genotypic classification. The G2encoding protein sequence (positions 2721 to 2946) of 70 viruses and the $\mathrm{N}$ conserved region of the $\mathrm{S}$ segment (nt 69 to 219) of 32 viruses have been amplified, subjectly to sequence analysis, and studied for that purpose. After alignment, the percentages of similarities were calculated. A frequency distribution of similarity percentages obtained from the G2 fragment region indicates that similarities segregate mainly into three ranges. Similarities were high ( 90 to $100 \%)$ between viruses of the same lineage. Similarities were intermediate (74 to $86 \%$ ) between viruses of different lineages or different viruses characterized from the five countries in South America studied (e.g., LN and AND). Similarities were low (63 to 78\%) for two viruses from different hemispheres or between different North American viruses (e.g., AND Sout and SN or BY and NY) (Fig. 4). Similarities for the N conserved region of $151 \mathrm{bp}$ from viruses of the same or different lineages more frequently overlap each other (data not shown). 


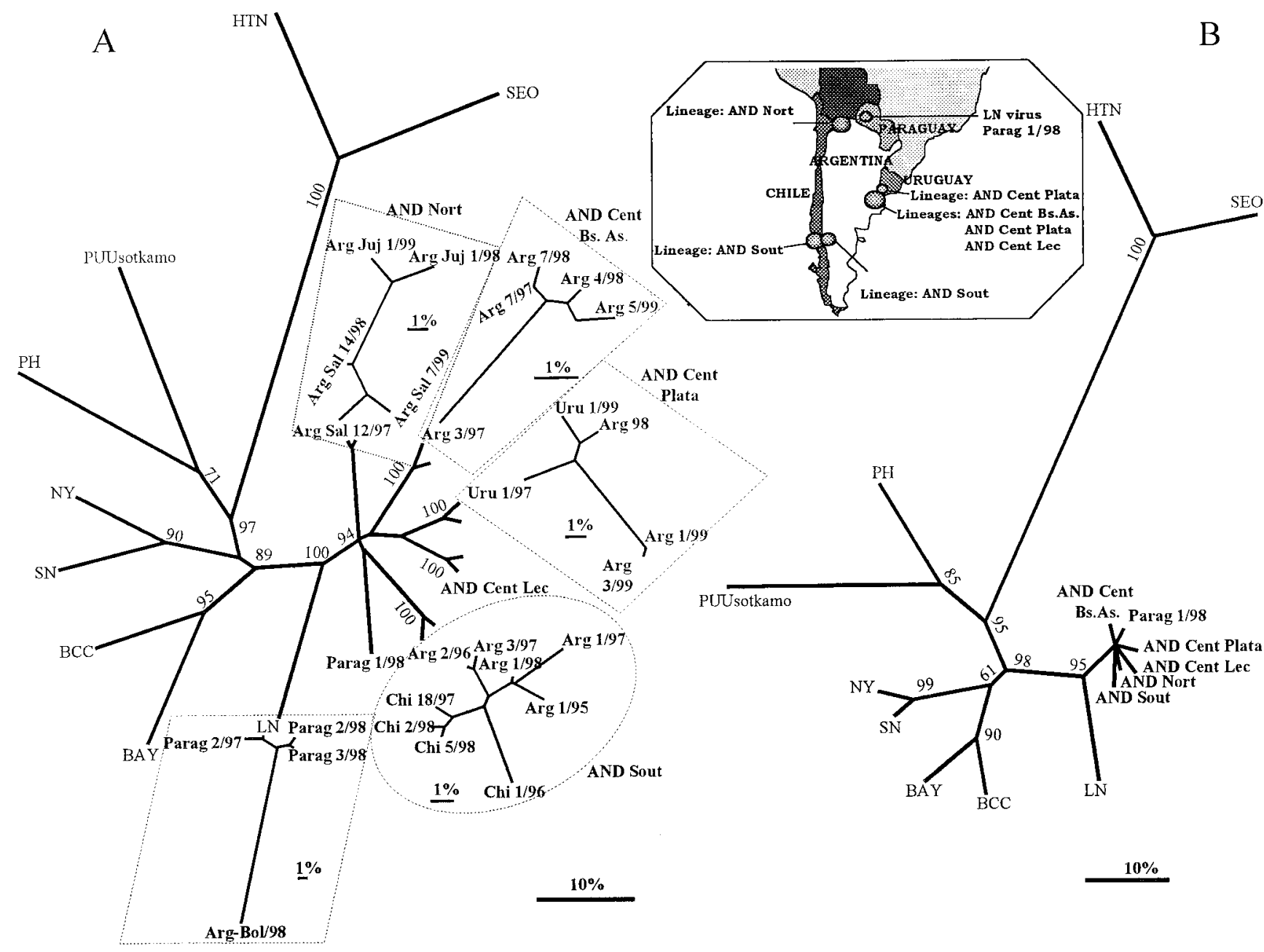

FIG. 3. Phylogenetic relationship of hantaviruses based on nucleotide and amino acid sequences of three M-segment PCR fragments (nt 88 to 281 and 1736 to 1987 of G1 and nt 2721 to 2946 of G2). The lengths of the lines are proportional to genetic distances. The values next to the branches indicate the bootstrapping confidence limits (as percentages) from 500 replicates. (A) Nucleotide sequences were analyzed by the MP method (DNAPARS) using the PHYLIP package. Viral sequences geographically related to representative cases for each lineage are shown within the dotted lines. (B) Putative amino acid sequences were analyzed by the MP method (PROTPARS) using the PHYLIP package. The map shows the geographic distribution of the different virus lineages related to HPS cases. Sequences shown in roman type (not bold) were obtained from GeneBank.

Incubation period of Andes virus. The occurrence of interhuman transmission makes follow up of HPS contacts crucial. The available estimation of the incubation period was 4 to 42 days for HFRS (11) and 2 to 3 weeks for SN virus infection (10).

TABLE 1. Nucleotide and amino acid sequence identity percentages between different AND virus lineages

\begin{tabular}{lccccc}
\hline \multirow{4}{*}{ AND virus } & \multicolumn{5}{c}{ Identity between AND virus lineages ${ }^{a}$} \\
\cline { 2 - 6 } & $\begin{array}{c}\text { AND } \\
\text { Sout }\end{array}$ & $\begin{array}{c}\text { AND } \\
\text { Nort }\end{array}$ & $\begin{array}{c}\text { AND Cent } \\
\text { Bs.As. }\end{array}$ & $\begin{array}{c}\text { AND } \\
\text { Cent Lec }\end{array}$ & $\begin{array}{c}\text { AND } \\
\text { Cent Plata }\end{array}$ \\
\hline AND Sout & - & 78.8 & 76.5 & 77.4 & 78.7 \\
AND Nort & 92.3 & - & 80.4 & 80.6 & 80.1 \\
AND Cent Bs.As. & 92.3 & 93.7 & - & 80.8 & 80.0 \\
AND Cent Lec & 91.9 & 93.7 & 94.1 & - & 86.6 \\
AND Cent Plata & 92.3 & 94.6 & 94.1 & 96.9 & - \\
\hline
\end{tabular}

${ }^{a}$ Comparisons were done on $446 \mathrm{nt}$ from the G1-coding region and $226 \mathrm{nt}$ from the G2-coding region. Values above dashes (which indicate $100 \%$ identity) are nucleotide sequence comparisons, and those below the dashes are deduced amino acid sequence comparisons.
In order to estimate the incubation period for AND virus infection in person-to-person transmission, we performed a combinatory approach to find a mean and standard deviation, assuming that the incubation period follows a normal distribution. The best-known epidemiological cases with the following restrictions were considered. (i) Each case B was in contact between days 4 to 50 before onset of symptoms with only one previous HPS case named A. (ii) Viral nucleotide sequences found in both cases must be identical (at least in 1,000 bp of the $\mathrm{S}$ and/or $\mathrm{M}$ segment). (iii) No exposure to rodents should be recorded for case $\mathrm{B}$ during the 50 days before the onset of the symptoms. Six cases with these restrictions were available. The actual intervals between the onset of A and B symptoms in the six cases considered were 16, 18, 19, 21, 25, and 29 days.

The following three assumptions were used. (i) The infectivity $\inf _{\mathrm{Aj}}$, defined as the conditional probability of the infection due to contact between HPS case A and a noninfected person on day $\mathrm{j}$, follows a normal distribution with a maximum value at the day of the onset of symptoms in case $\mathrm{A}$ and a standard deviation equal to 2 days. (ii) Only one infection 


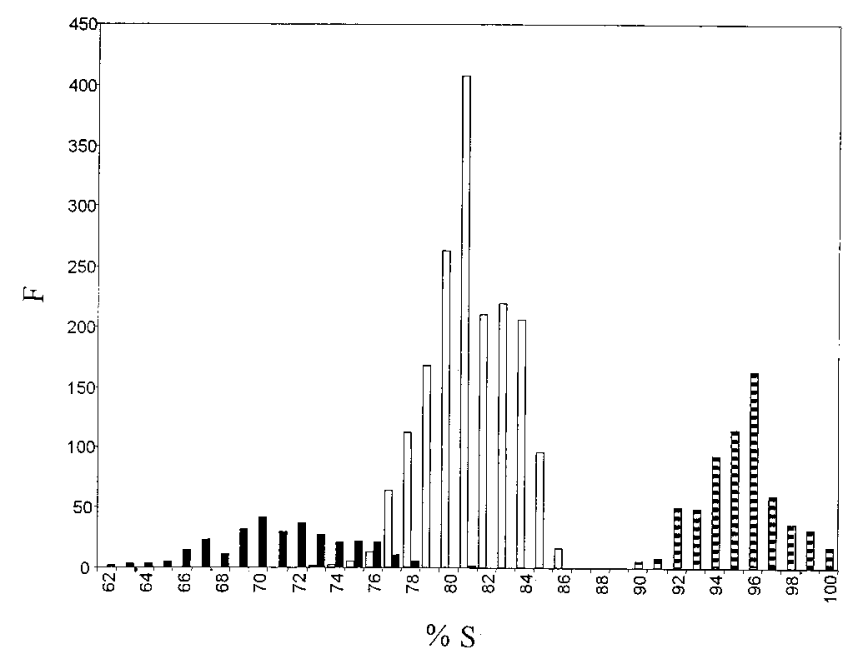

FIG. 4. Sequence comparisons of the different Andes lineages and American HPS hantaviruses. The frequency $(F)$ versus the percentage of similarity (S) from a total of 76 samples obtained after comparison of 5,700 paired sequences of a 226-nt G2 fragment (nt 2721 to 2946). Striped bars represent different sequences belonging to the same AND lineage. White bars represent sequences belonging to different AND lineages or viruses from the six countries in South America studied. Black bars represent North American HPS viruses, American viruses, or viruses from different hemispheres. The AND lineages include 14 AND Nort samples, 16 AND Cent Bs.As. samples, 5 AND Cent Plata sequences, 3 AND Cent Lec sequences, and 29 AND Sout sequences. North American HPS viruses include SN, NY, BCC, and BAY. South American HPS viruses include LN, Parag3/98, Parag1/98, and Arg-Bol/98. MACIEL virus was also included in the analysis.

event was considered. (iii) The incubation period of case $\mathrm{B}$ follows a normal distribution with mean $X$ and standard deviation $s$, both to be estimated. The probability of case $\mathrm{B}\left(p_{\mathrm{Bj}}\right)$ acquiring the infection on day j was calculated using $X$ and $s$.

The relative probability $\left(I_{\mathrm{ABj}}\right)$ of case $\mathrm{B}$ being infected by case $\mathrm{A}$ on day $\mathrm{j}$ is given by $I_{\mathrm{ABj}}=\inf _{\mathrm{Aj}} p_{\mathrm{Bj}} c_{\mathrm{ABj}}$, where $\mathrm{C}_{\mathrm{ABj}}$ is zero if $\mathrm{A}$ and $\mathrm{B}$ have not been in contact and one if there was contact between $\mathrm{A}$ and $\mathrm{B}$. In order to find the $X$ and $\sigma$ pair that gives the best fit with our data, we defined the function $\Theta$ as $\prod_{n=1}^{6} \sum_{j=-4}^{-50} I_{\mathrm{ABj}}$, where $j$ varies between -4 and -50 days.

Day zero corresponds to the onset of symptoms in case B. $\Theta$ resembles a probability function taking all the cases into account. $\Theta$ values were calculated using all combinations of $X$ and $\sigma$ ( $X$ varying between 4 and 50 and $\sigma$ varying between 0 and 15 , using a 0.2 step). The maximum value of $\Theta$ was obtained with $X=19.2$ and $s=5.2$.

On the basis of the limited data and the assumptions mentioned above, the incubation period for $85 \%$ of the cases would be days 12 to 27 . These values could be used as estimates for the periods that the HPS case contacts should be followed up.

\section{DISCUSSION}

We consider clinical, immunological, and virological data from 87 HPS cases from five countries of South America: Argentina, the country with the highest number of reported HPS cases, Bolivia, Chile, Paraguay, and Uruguay (which had 233, 397, 41, and 16 total cases, including those from 1999, respectively). The clinical presentation of HPS cases varied from moderate to severe. Multiple factors could be associated with different mortality rates in each region including variation in medical therapies, difference in pathogenesis of local virus, or HLA haplotype prevalence. Clinical and laboratory findings were similar in all regions studied, including patients with renal compromise or hemorrhagic signs. However, human-to-human transmission was reported only in South Argentina and Chile $(6,19,27,29)$. The decrease of mortality in recent years may be related to the improvement of diagnostic methods and medical treatments, but any association between the mortality rate or severity of infection with a particular lineage cannot be determined yet. The presence of two or more hantaviruses in a region is another factor to be considered in mortality rate analyses.

An early and strong $\operatorname{IgM}, \operatorname{IgA}$, and $\mathrm{IgG}$ humoral response was observed in almost all HPS cases. Low IgG titers or the absence of IgG has been associated with a higher mortality rate and leads to the question of the involvement of $\mathrm{IgG}$ antibodies in protection, although it should be noted that $\mathrm{N}$ protein does not stimulate a neutralizing antibody response. In a previous report, three Argentinean children with no detectable $\mathrm{IgG}$ response to $\mathrm{SN}$ virus antigens died (22). From a clinical perspective, a median as cutoff point seems to be an arbitrary value; however, on the basis of these results, we found that patients with higher IgG-specific response have a low probability of dying from the infection. A lower $\mathrm{IgG}$ response combined with other markers may be useful in identifying patients with higher mortality risk. Determination of the incubation period could be useful to establish the place where a traveler may have been infected and to analyze the transmission chain in complex situations. For this determination, we consider the highest infectivity to be near the onset of symptoms based on observations of AND interhuman transmission. For SN infection, a recent report showed a high level of viremia present on the day edema occurred, followed by a rapid decrease (26). Knowledge of the period of incubation and prognosis markers can contribute to the follow up of the contacts and treatment of the patients.

The IgA response reaches high levels in patient sera around day 15 and rapidly decreases at the end of the acute phase. These antibodies could be used together with IgM and IgG to improve the diagnostic accuracy of cases with low IgM response values in order to define the stage of infection in patients in which the course of infection is atypical. In addition, detection of $\operatorname{IgA}$ in saliva could be an important tool in populations where it is not possible to obtain blood by venipuncture due to cultural reasons (20). Lack of detection of $\operatorname{IgM}$ antibodies in sera from the two patients reported here could be caused by a reinfection event. However, for hantaviruses, reinfection has not been described. ELISA was performed three times in the unique sample from each case available with identical results ( 2 and 4 days after onset of symptoms).

Viral RNA is regularly detected in patients with acute infections. The presence of virus and our ability to detect viral genome in HPS contact patients by RT-PCR at least 7 days prior to the onset of symptoms showed that this test could be useful in deciding early antiviral therapies.

For a better understanding of the variability of these viruses in South America, partial M and S segments were analyzed. Phylogenetic analysis based on partial M-fragment G1- and G2-encoding sequences showed that HPS cases from Argentina, Chile, Paraguay, and Uruguay were infected with AND or LN viruses. Within AND virus-infected persons, at least five major lineages were found, two present in distant geographical regions and three in contiguous regions. Variants from Patagonia, southern Argentina, and Chile named AND Sout, clustered with the first virus characterized for the region (13). This lineage included sequences related with person-to-person transmission. A new lineage was found in HPS cases from both sides of the Rio de la Plata river (AND Cent Plata). It was 
shown in Oligoryzomys studies that passive transport of animals would promote unidirectional gene flow along the river and lack of isolation by distance (3). In one locality of Buenos Aires province, two viral lineages, AND Cent Plata and AND Cent Bs.As., were associated with HPS cases. We found a maximum nucleotide divergence of $23.5 \%$ between AND Sout and AND Cent Bs.As. and a minimum value of $13.4 \%$ between AND Cent Plata and AND Cent Lec. However, in all comparisons, amino acid divergence is between 3 to $8 \%$. Neither the genotypes Pergamino and Maciel characterized previously in the central Argentine region from Akodon azarae and Necromys obscurus (ex Bolomys), respectively, nor the Bermejo genotype from Oligoryzomys chacoensis in North Argentina reported (12) was found in human cases. However, the fact that Pergamino and Maciel genotypes have not been demonstrated in human cases may just mean that rodent species reservoirs have not undergone a population explosion.

Two Paraguayan patients were infected with a virus different from LN, the only causative agent of HPS reported in Paraguay. According to the results of phylogenetic analyses, this virus could probably be considered a new lineage more related to AND virus lineages than to LN virus (Fig. 3), suggesting that a Oligoryzomys-borne viral variant is probably circulating. In fact, this rodent genus is known to be circulating in Paraguay (16). Seropositive Oligoryzomys rodents are present in the three areas in Argentina where hantavirus is endemic (2). Moreover, hantavirus from Bolivia (1) and Peru (24) were associated with $O$. microtis. These findings show the importance of Oligoryzomys rodents in the maintenance of hantaviruses in South America.

The definition of hantavirus species is under discussion. In order to assign this taxonomic status, several criteria have been taken into account: (i) serological criterion based on crossneutralization assays, (ii) genetic criterion based on sequence similarities, and (iii) a geographical-ecological criterion based on maintenance and coevolution in different primary rodent reservoirs. A direct relationship between genetic and serological data is difficult to show, but this traditional criterion correlates remarkably well with molecular data. Lower amino acid divergences are regularly related with cross neutralization (15).

So far, the viruses associated to human infections in the region are closely related to Oligoryzomys-borne viruses (12). As shown in Fig. 3B, phylogenetic analysis based on amino acid comparisons show a close relationship between these viruses. Despite nucleotide sequence diversity in Oligoryzomys-borne related virus-deduced amino acid sequences were highly conserved, indicating a strong evolutionary pressure to maintain the sequence integrity, suggesting a high adaptation of the virus among the different rodents of this genus. Two lineages can be found in a rodent species like AND Sout and AND Nort in Oligoryzomys longicaudatus (12). On the other hand, the same viral lineage was found in three different Oligoryzomys species (data not shown). In our opinion, there are not yet enough reasons to consider these different lineages as independent viruses. Species jumping (host switching) may have occurred, and Dobrava virus has been demonstrated in two rodent species $(15,21,28)$. The relationships within the Oligoryzomys genus are not clearly known (17). Additional rodent phylogenetic studies and long-term studies for the determination of rodent-virus association should be useful in addition to cross neutralization assays in order to clarify this issue. We suggest naming these lineages Andes and adding a geographical reference as is usually done for hantaviruses.

A thorough analysis of new genotypes ultimately requires sequencing of their complete genomes, but sequencing of two sufficiently large regions such as the beginning of the G1- and
G2-coding regions seems to provide a reliable alternative to the complete genome. The conserved $\mathrm{N}$-coding region contains insufficient sequence diversity to be able to distinguish genotypes by phylogenetic analysis. However, the G2-coding region, extensively used for $\mathrm{SN}$ virus (15) may be employed for routine genotyping, since primers used are within a region highly conserved to allow PCR amplification even though providing differentiation. In our geographical region, similarity analysis of G2-encoding M-segment fragment (nt 2721 to 2946) was shown to be useful for the identification of lineages.

The results presented here provide new information on HPS virus variability in five countries in South America including the description of at least one new AND lineage (and probably two). Determining the variants involved in human disease can be useful in order to improve control measures. Recently, genetic investigation has revealed the presence of novel hantaviruses in Brazil, some of which appear to be more closely related to the Argentinean viruses than to each other (8).

Although this study involved an overview of hantavirus infection in South America, many more viruses will probably be reported in the future, and much more data will be necessary for understanding hantavirus diversity and evolution.

\section{ACKNOWLEDGMENTS}

We gratefully acknowledge the contributions of Daniel Gutson in mathematics. We also thank Juan Carnival for helpful clinical discussions. Special thanks go to Maria Cristina Oses for technical support.

\section{REFERENCES}

1. Bharadwaj, M., J. Botten, N. Torrez-Martinez, and B. Hjelle, 1997. Rio Mamore virus: genetic characterization of a newly recognized hantavirus of the pygmy rice rat, Oligoryzomys microtis, from Bolivia. Am. J. Trop. Med. Hyg. 57:368-374.

2. Calderon, G., N. C. Pini, J. Bolpe, S. Levis, J. Mills, E. L. Segura, N. Guthmann, G. Cantoni, J. Becker, A. Fonollat, C. Ripoll, M. Bortman, R. Benedetti, M. Sabattini, and D. A. Enria. 1999. Hantavirus reservoir hosts associated with peridomestic habitants in Argentina. Emerg. Infect. Dis. vol. 5. [Online.] http://www.cdc.gov/ncidod/EID/vol5no6/calderon.htm.

3. Chiappero, M. B., G. E. Calderon, and C. N. Gardenal. 1997. Oligoryzomys flavescens (Rodentia, Muridae): gene flow among populations from centraleastern Argentina. Genetica 101:105-113.

4. Duchin, J. S., F. T. Koster, C. J. Peters, G. L. Simpson, B. Tempest, S. R. Zaki, T. G. Ksiazek, P. E. Rollin, S. Nichol, E. T. Umland, R. L. Moolenaar, S. E. Reef, K. B. Nolte, M. M. Gallher, J. C. Butler, R. F. Breiman, and The Hantavirus Study Group. 1994. Hantavirus pulmonary syndrome: a clinical description of 17 patients with a newly recognized disease. N. Engl. J. Med. 330:949-955.

5. Elliott, R. M., C. S. Schmaljohn, and M. S. Collet. 1991. Bunyavirus genome structure and gene expression. Curr. Top. Microbiol. Immunol. 169:91-141.

6. Enria, D., P. Padula, E. L. Segura, N. Pini, A. Edelstein, C. Riva Posse, and M. C. Weissenbacher. 1996. Hantavirus pulmonary syndrome in Argentina. Possibility of person-to-person transmission. Medicina 56:709-711.

7. Ferrer, J. F., C. B. Jonsson, E. Esteban, D. Galligan, M. A. Basombrio, M. Peralta-Ramos, M. Bharadwaj, N. Torrez-Martinez, J. Callahan, A. Segovia, and B. Hjelle. 1998. High prevalence of hantavirus infection in Indian communities of the Paraguayan and Argentinean Gran Chaco. Am. J. Trop. Med. Hyg. 59:438-444.

8. Johnson, A. M., L. T. de Souza, I. B. Ferreira, L. E. Pereira, T. G. Ksiazek, P. E. Rolling, C. J. Peters, and S. T. Nichol. 1999. Genetic investigation of novel hantaviruses causing fatal HPS in Brazil. J. Med. Virol. 59:527-535.

9. Khan, A. S., T. G. Ksiazek, and C. J. Peters. 1996. Hantavirus pulmonary syndrome. Lancet 347:739-741.

10. Koster, F., and H. Levy. 1999. Clinical manifestations and treatment of HPS, p. 33-38. In W. H. Lee, C. Calisher, and C. Schmaljohn (ed.), Manual of hemorrhagic with renal syndrome and hantavirus pulmonary syndrome. WHO Collaborating Center for Virus Reference and Research (Hantaviruses). Asan Institute for Life Sciences, Seoul, Korea.

11. Lee, J. S. 1999. Clinical manifestations and treatment of HFRS and HPS, p. 18-27. In W. H. Lee, C. Calisher, and C. Schmaljohn (ed.), Manual of hemorrhagic fever with renal syndrome and hantavirus pulmonary syndrome. WHO Collaborating Center for Virus Reference and Research (Hantaviruses). Asan Institute for Life Sciences, Seoul, Korea.

12. Levis, S., S. Morzunov, J. Rowe, D. A. Enria, N. Pini, G. Calderon, M. Sabattini, and S. C. St. Jeor. 1998. Genetic diversity and epidemiology of hantaviruses in Argentina. J. Infect. Dis. 177:529-538. 
13. López, N., P. Padula, C. Rossi, M. E. Lázaro, and M. T. Franze-Fernández. 1996. Genetic identification of a new hantavirus causing severe pulmonary syndrome in Argentina. Virology 220:223-226.

14. López, N., P. Padula, C. Rossi, S. Miguel, A. Edelstein, E. Ramírez, and M. T. Franze-Fernández. 1997. Genetic characterization and phylogeny of Andes virus and variants from Argentina and Chile. Virus Res. 50:77-84.

15. Monroe, M. C., S. P. Morzunov, A. M. Johnson, M. D. Bowen, H. Artsob, T. Yates, C. J. Peters, P. E. Rollin, T. G. Ksiazek, and S. T. Nichol. 1999. Genetic diversity and distribution of Peromyscus-borne hantaviruses in North America. Emerg. Infect. Dis. 5:75-86.

16. Musser, G. G., and M. D. Carleton. 1993. Family Muridae, p. 501-755. In D. E. Wilson and D. M. Reeder (ed.), Mammal species of the world. Smithsonian Institution Press, Washington, D.C.

17. Myers, P., B. Lundrigan, and P. K. Tucker. 1995. Molecular phylogenetics of oryzomyine rodents: the genus Oligoryzomys. Mol. Phylogenet. Evol. 4:372-382.

18. Nichol, S. T., C. F. Spiropoulou, S. Morzunov, P. E. Rolling, T. G. Ksiazek, H. Feldmann, A. Sanchez, J. Childs, S. Zaki, and C. J. Peters. 1993. Genetic identification of a hantavirus associated with an outbreak of acute respiratory illness. Science 262:914-917.

19. Padula, P. J., A. Edelstein, S. D. L. Miguel, N. M. López, C. M. Rossi, and R. D. Rabinovich. 1998. Hantavirus pulmonary syndrome outbreak in Argentina: molecular evidence for person-to-person transmission of Andes virus. Virology 241:323-330.

20. Padula, P. J., C. M. Rossi, M. O. Della Valle, V. P. Martínez, S. B. Colavecchia, A. Edelstein, S. D. L. Miguel, R. D. Rabinovich, and E. L. Segura. Development and evaluation of a solid phase enzyme immunoassay based on Andes hantavirus recombinant nucleoprotein. J. Med. Microbiol., in press.

21. Peters, C. J. 1998. Hantavirus pulmonary syndrome in the Americas. Emerg. Infect. 2:17-64.

22. Pini, N. C., A. Resa, G. del J. Laime, G. Lecot, T. G. Kziazek, S. Levis, and D. A. Enria. 1998. Hantavirus infection in children in Argentina. Emerg. Infect. Dis. 4:85-87.
23. Plyusnin, A., O. Vapalahti, and A. Vaheri. 1996. Hantaviruses: genome structure, expression and evolution. J. Gen. Virol. 77:2677-2687.

24. Powers, A. M., D. R. Mercer, D. M. Watts, H. Guzman, C. F. Fulhorst, V. L. Popov, and R. B. Tesh. 1999. Isolation and genetic characterization of a hantavirus (Bunyaviridae: Hantavirus) from a rodent, Oligoryzomys microtis (Muridae), collected in northeastern Peru. Am. J. Trop. Med. Hyg. 61:92-98.

25. Schmaljohn, C., and B. Hjelle. 1997. Hantavirus: a global disease problem. Emerg. Infect. Dis. 3:95-104.

26. Terajima, M., J. D. Hendershot III, H. Kariwa, F. T. Koster, B. Hjelle, D. Goade, M. C. DeFronzo, and F. A. Ennis. 1999. High level of viremia in patients with the hantavirus pulmonary syndrome. J. Infect. Dis. 180:2030 2034.

27. Toro, J., J. D. Vega, A. S. Khan, J. N. Mills, P. J. Padula, W. Terry, Z. Yadón, R. Valderrama, B. A. Ellis, C. Pavletic, R. Cerda, S. Zaki, S. Wun-Ju, R. Meyer, M. Tapia, C. Mansilla, M. Baro, J. A. Vergara, M. Concha, G. Calderón, D. Enria, C. J. Peters, and T. G. Ksiazek. 1998. An outbreak of hantavirus pulmonary syndrome, Chile, 1997. Emerg. Infect. Dis. 4:687-694.

28. Vapalahti, O., A. Lundkvist, V. Fedorov, C. J. Conroy, S. Hirvonen, A. Plyusnina, K. Nemirov, K. Fredga, J. A. Cook, J. Niemimaa, A. Kaikusalo, H. Henttonen, A. Vaheri, and A. Plyusnin. 1999. Isolation and characterization of a hantavirus from Lemmus sibiricus: evidence for host switch during hantavirus evolution. J. Virol. 73:5586-5592.

29. Wells, R. M., S. Sosa Stani, Z. E. Yadón, E. Enria, P. Padula, N. Pini, J. N. Mills, C. J. Peters, E. L. Segura, and The Hantavirus Pulmonary Syndrome Study Group for Patagonia. 1997. An unusual hantavirus outbreak in southern Argentina: person-to-person transmission? Emerg. Infect. Dis. 3:171174.

30. Williams, R. J., R. T. Bryan, J. N. Mills, R. E. Palma, I. Vera, F. Velasquez, E. M. Baez, W. E. Schmidt, R. E. Figueroa, C. J. Peters, S. R. Zaki, A. S. Khan, and T. G. Ksiazek. 1997. An outbreak of hantavirus pulmonary syndrome in western Paraguay. Am. J. Trop. Med. Hyg. 57:274-282. 